\title{
On the influence of psychrometric ambient conditions on cooling tower drift deposition
}

\author{
M. Lucas ${ }^{1 *}$, P.J. Martínez ${ }^{1}$, J. Ruiz ${ }^{1}$, A. Sánchez-Kaiser ${ }^{2}$, A. Viedma ${ }^{2}$ \\ ${ }^{1}$ Departamento Ingeniería de Sistemas Industriales, Universidad Miguel Hernández \\ Avda. de la Universidad, s/n, 03202 Elche, España \\ Telephone: $966658887 \quad$ Fax: 966658979 \\ e-mail: mlucas@umh.es \\ 2 Departamento de Ingeniería Térmica y de Fluidos \\ Universidad Politécnica de Cartagena (Campus Muralla del Mar) \\ Dr. Fleming, s/n, 30202 Cartagena, España
}

\begin{abstract}
Water drift emitted from cooling towers is objectionable for several reasons, mainly due to human health reasons. A numerical model to study the influence of psychrometric ambient conditions on cooling tower drift deposition was developed. The mathematical model presented, consisting of two coupled sets of conservation equations for the continuous and discrete phases, was incorporated in the general purpose CFD code Fluent. Both experimental plume performance and drift deposition were employed to validate the numerical results. This study shows the influence of variables like ambient dry bulb temperature, ambient absolute humidity and droplet exit temperature from cooling tower on the drift evaporation (and therefore deposition) and on the zone affected by the cooling tower. The stronger effect detected corresponds to the ambient dry bulb temperature. When a higher ambient temperature was present, deposition was lower (evaporation was therefore higher) and the zone affected by the cooling tower was smaller. The influence of the other two variables included in the study was weaker than the one corresponding to the dry bulb ambient temperature. A high level of ambient absolute humidity increased drift deposition and also the size of the zone affected by the cooling tower. Finally, a high level of droplet exit temperature decreased deposition and increased the zone affected by the cooling tower.

Keywords: Cooling towers, drift, legionaries' disease, CFD, deposition.
\end{abstract}




\section{Nomenclature}

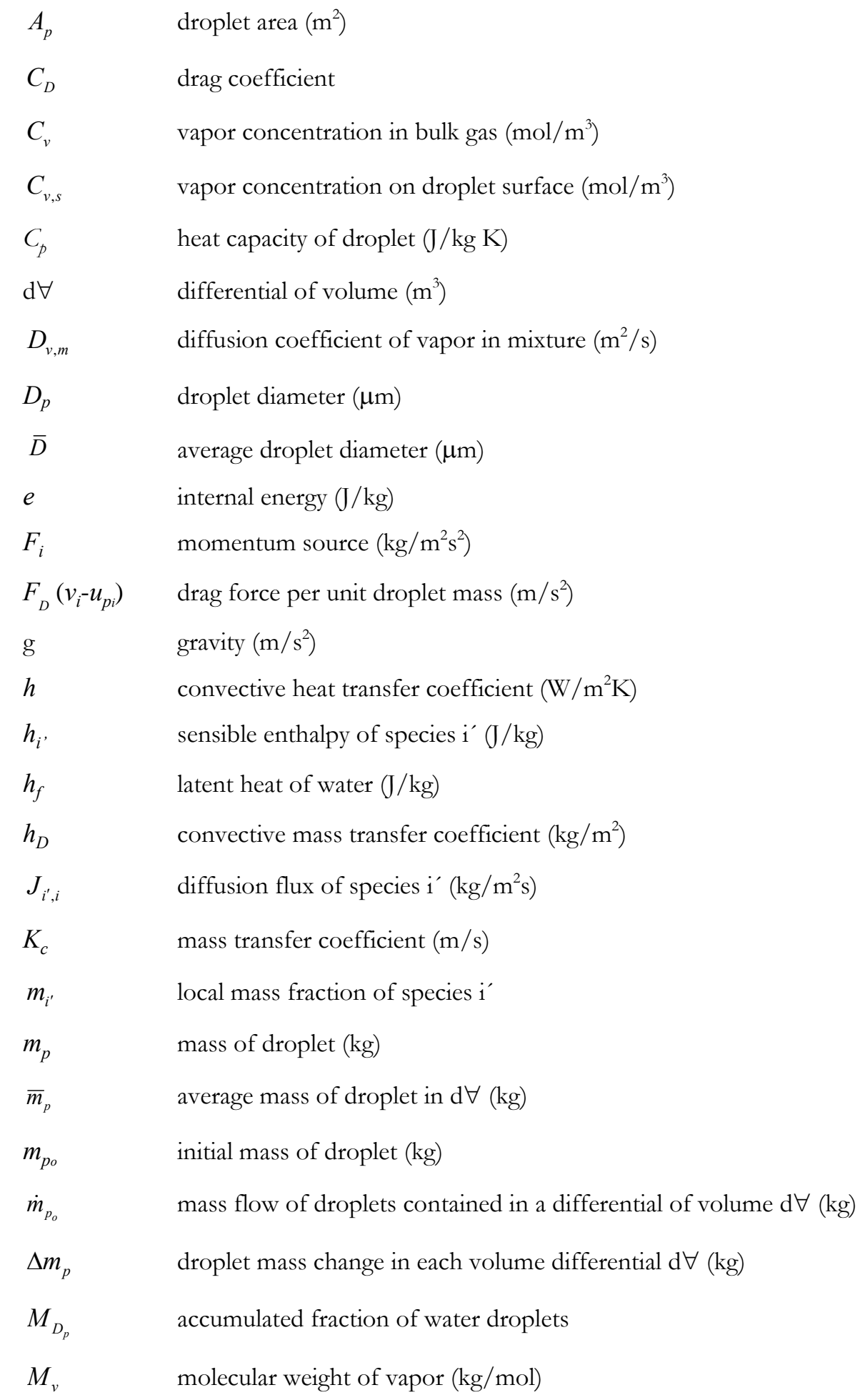




$\begin{array}{ll}n & \text { fit coefficient in Rosin-Rambler's equation } \\ N_{v} & \text { molar flux of vapor }\left(\mathrm{mol} / \mathrm{m}^{2} \mathrm{~s}\right) \\ \mathrm{Nu} & \text { Nusselt number } \\ p & \text { static pressure }(\mathrm{Pa}) \\ p_{v s} & \text { saturated vapor pressure }(\mathrm{Pa}) \\ R & \text { universal gas constant }\left(\mathrm{kg} \mathrm{m}^{2} / \mathrm{s}^{2} \mathrm{~K} \text { mol }\right) \\ \mathrm{Re} & \text { Reynolds number } \\ S_{i^{\prime}} & \text { mass flow source }\left(\mathrm{kg} / \mathrm{m}^{3} \mathrm{~s}\right) \\ S_{h} & \text { volumetric heat source }\left(\mathrm{kg} / \mathrm{s}^{3} \mathrm{~m}\right) \\ T & \text { air temperature }(\mathrm{K}) \\ T_{p} & \text { temperature of the droplet }(\mathrm{K}) \\ T_{r e f} & \text { reference temperature for enthalpy }(\mathrm{K}) \\ T_{\infty} & \text { ambient temperature of continuous phase at domain inlet }(\mathrm{K}) \\ T_{o} & \text { velocity of the droplet }(\mathrm{m} / \mathrm{s}) \\ \Delta T_{p} & \text { temperature change of droplet in } \mathrm{d} \forall(\mathrm{K}) \\ \mathrm{V}_{\mathrm{p}} & \text { air velocity component at the y axis }(\mathrm{m} / \mathrm{s}) \\ v & \end{array}$

\section{Greek symbols}

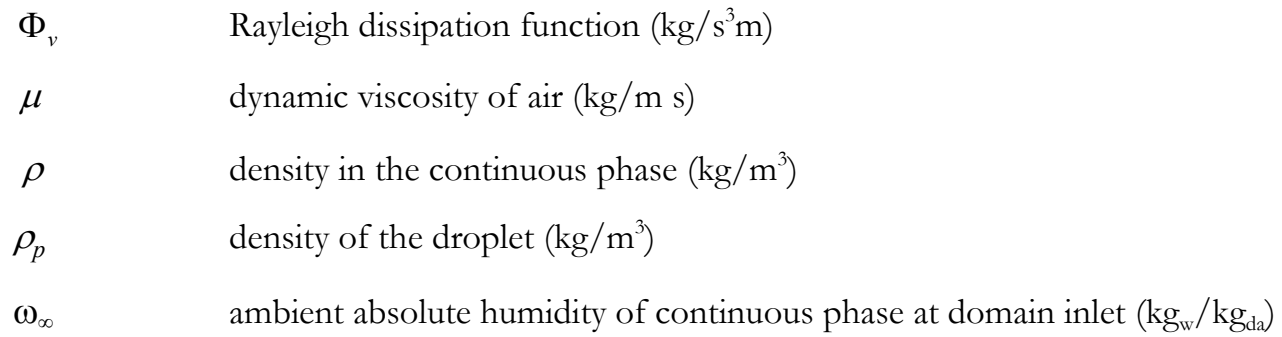


Subscripts

a air

d dry

$i^{\prime} \quad$ species

$p \quad$ for droplet (particle)

$v \quad$ vapor

w water 


\section{Introduction}

Cooling towers are evaporative heat transfer devices in which atmospheric air cools warm water, with direct contact between the water and the air, by evaporating part of the water. They are commonly used to dissipate heat from power plants, water-cooled refrigeration, air conditioning and industrial processes. The principle of operation of cooling towers requires distributing or spraying water over a heat transfer surface across or through which a stream of air is passing. As a result, water droplets are incorporated in the air stream and, depending on the velocity of the air, will be taken away from the unit. This is known as drift and it is independent of water lost by evaporation.

Cooling tower drift is objectionable for several reasons (Lewis, 1974). Initial interest in drift was associated with dispersion of radioactive particles from nuclear accidents or nuclear power plant sites (Pasquill, 1962; Van der Hoven, 1968). Later, the impact of accumulated salts on downwind vegetation associated with large ocean side fossil and nuclear power plants using salt-water or brackish water in natural and mechanical draft cooling towers drove investigations into drift behaviour (ASME, 1975). Corrosions problems ensued on equipment, piping and structural steel or ice formation during winter months are cited by Pedersen, 1987. Drift also represents an emission of chemicals or microorganisms to the atmosphere. Undoubtedly the most well known pathogens are the multiple species of bacteria collectively known as legionella. These bacteria tend to thrive at the range of water temperatures frequently found in these cooling systems. Hence, workers or other people near a cooling tower may be exposed to drift, may inhale aerosols containing the legionella bacteria, and may become infected. Several legionella outbreaks have been linked to cooling towers (Bentham and Broadbent, 1993; and Isozumi et al., 2005).

Both for the environmental impact assessment of a cooling tower, and for the detection of the origin of an outbreak of Legionnaire's disease, it is interesting to have a model that predicts the affected area by a cooling tower. Wilmot et al., 2000, established a Bayesian Belief Network (BBN) to model the uncertainty of aerosols released from cooling towers and a Geographic Information System (GIS) to create a wind dispersion model and identify potential cooling towers as the source of infection. They constructed a very simple binormal plume dispersion model to update the probability of a cooling tower infection given a case of Legionella. Brown et al., 1999, presented an epidemiological method to 
calculate dose of exposure to a source of Legionnaire's disease infection. They defined a variable, called Aerosol Exposure Units $(A E U=t / d)$, which relates the time $(t)$ spent at distance (d) from the source. Both references carried out a simulation of the cooling tower drift dispersion very simple, and therefore limited.

The movement of gases and fine aerosols from cooling tower exits can be predicted by analytic programs (such as the Industrial Source Complex (ISC3) Dispersion Models, US EPA (1995), or the Seasonal/Annual Cooling Tower Impact (SACTI) Model, Policastro et al. (1981)). Unfortunately, neither of these approaches allows including the influence of nearby large buildings on the flow fields, which affect the local building downwash and cooling tower drift. When significant building interactions are present, physical modelling in environmental wind tunnels are used. The background flow fields and gaseous plume motions can be accurately predicted by physical modelling in environmental wind tunnels at moderate velocities. However, the correct scaling of droplet and particle drift requires the simulations to be run at extremely low facility velocities, which distorts the model flow fields (Kennedy and Fordyce, 1974; Jain and Kennedy, 1978; Petersen, 2004). A comparative between dispersion experiments in a wind tunnel and the ones obtained with dispersion model AUSTAL2000 can be found in Bahmann and Schmonsees, 2004. They called amplification factors to the ratio of the ground level concentration values with and without buildings.

A third approach to estimate drift and droplet deposition which includes the effects of ambient winds, building wakes, exhaust jets and surrounding buildings and terrain is that of computational fluid dynamics (CFD) solving the relevant equations of motion by numerical methods. Bender et al., 1993, reported the results of a 2-dimensional simulation of the interaction of the flow through an idealized cooling tower with the wind flow over the tower. Takata et al., 1996, calculated the effects of wind on the visible envelope of moist cooling tower plumes using CFD. Bornoff et al., 2001, presented the results of a numerical investigation into the interaction of two adjacent plumes in a cross-flow. Riddle et al., 2004, compared CFD results with the predictions from the Atmospheric Dispersion Modelling System (ADMS) in geometrically complex situations as the case of buildings in close proximity. 
Meroney, 2006, developed a computational fluid dynamics model to simulate cooling tower plume dispersion and drift. He predicted drift deposition levels downwind a cooling tower. The simulation was prepared to replicate the Chalk Point Dye Tracer Experiment. These experiments are described in papers and reports by Hanna (1974) and Policastro et al. (1978a and 1978b). Although Meroney's model did not take into account drift droplets evaporation, it successfully predicted plume rise and droplet deposition observed during the 1977 Chalk Point dye tracer experiment. This work shows that recent improvements in numerical solution algorithms, increases in computational speed, new turbulence models and increased storage capacity in computers, make it possible to calculate reasonably large and complicated domains.

The objectives of the present work were three-fold: the first one was to develop a computational fluid dynamics model to predict water droplet dispersion and surface drift deposition from cooling towers. The second one was to validate the model by using experimental data from Chalk Point as reference. The third objective was to assess the influence of psychrometric ambient conditions (dry bulb temperature and absolute humidity) and water droplet exit temperature on drift deposition and on the size of the area affected by the cooling tower. 


\section{Modelling}

\subsection{Physical model}

The physical model employed in this paper is composed of a hyperbolic natural draught cooling tower located in a parallelepiped. The cooling tower modelled has a height of 124 $\mathrm{m}$, a base diameter of $114 \mathrm{~m}$ and an exit diameter of $54.8 \mathrm{~m}$. Simulation was performed on a domain with a length of $3000 \mathrm{~m}$, a width of $1000 \mathrm{~m}$ and a height of $750 \mathrm{~m}$. Ambient conditions like wind velocity, temperature and absolute humidity were set to as profiles. Conditions at exit cooling tower were defined by means of air velocity, temperature and absolute humidity. Water drift was characterized by a droplet size distribution.

The reference tower is situated at Chalk Point power plant (Maryland, U.S.A.) on a peninsula that extends into the local bay and wet lands. Chalk Point power plant is the largest generation station in Maryland. Its size is about $4.69 \mathrm{~km}^{2}$ and its capacity is approximately 2,415 GW. To dissipate heat from the condensers, brackish water from the bay is recirculated on two natural draft cooling towers. Although the objective of this work goes beyond the simulation of a particular cooling tower, Chalk Point geometry has been selected because drift deposition experimental data is available to validate the numerical model.

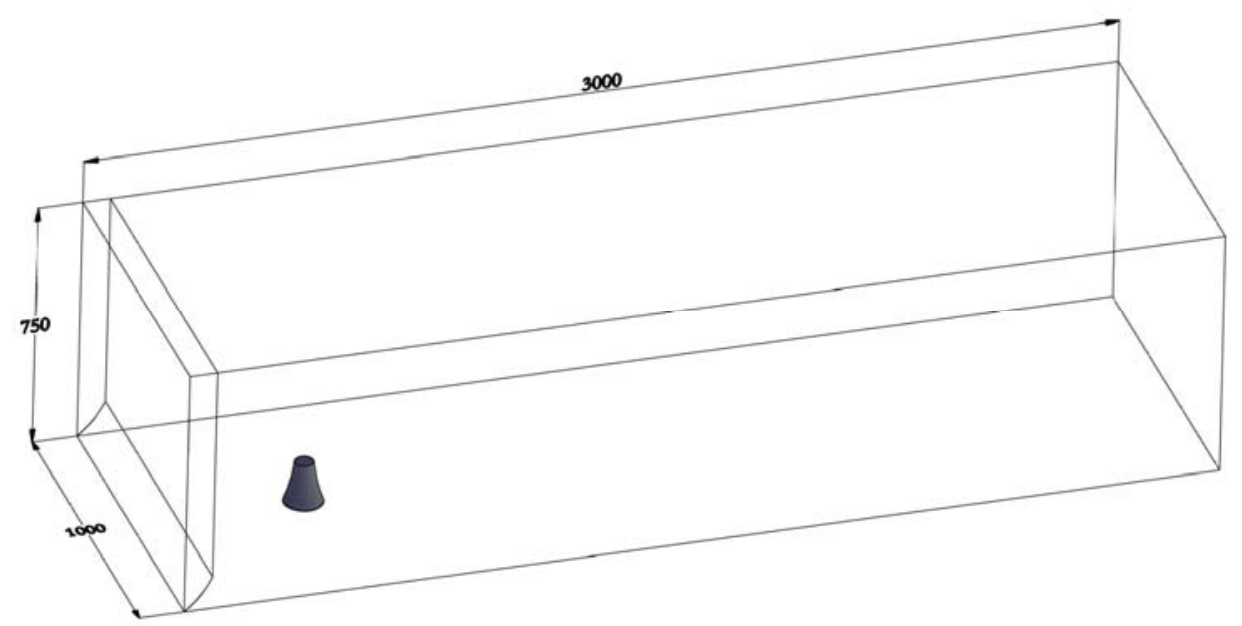

Figure 1: Physical model employed on numerical simulation. 


\subsection{Mathematical model}

Processes related to fluid flux and heat-and-mass transfer between different phases are governed by mass, momentum, energy and species conservation principles. These principles may be expressed by means of differential equations. In order to analyse the mathematical model of the problem that has been treated here, three groups of equations may be considered: the set of equations that governs the continuous phase (external cooling tower flow), the set of equations of the discrete phase (droplets of water escaped from cooling tower exit), and the set of equations that provides the chemical species (dry air and water vapor). The continuous and discrete phase equations are coupled by the source terms of the conservation equations.

\subsubsection{Continuous phase}

The equations of this phase are presented below.

$$
\begin{gathered}
\frac{\partial}{\partial x_{i}}\left(\rho v_{i}\right)=S_{i^{\prime}}, \\
\rho v_{j} \frac{\partial v_{i}}{\partial x_{j}}=\frac{\partial}{\partial x_{j}}\left[\mu\left(\frac{\partial v_{i}}{\partial x_{j}}+\frac{\partial v_{j}}{\partial x_{i}}\right)-\frac{2}{3} \mu\left(\frac{\partial v_{j}}{\partial x_{j}}\right) \delta_{i j}\right]+\rho g_{i}-\frac{\partial p}{\partial x_{i}}+F_{i}, \\
\rho v_{i} \frac{\partial e}{\partial x_{i}}=-p \frac{\partial v_{i}}{\partial x_{i}}+\Phi_{v}+\frac{\partial}{\partial x_{i}}\left(k \frac{\partial T}{\partial x_{i}}\right)+\frac{\partial}{\partial x_{i}}\left(\sum_{i^{\prime}=1}^{n} h_{i^{\prime}} J_{i^{\prime}}\right)+S_{h}, \\
\rho v_{i} \frac{\partial m_{i^{\prime}}}{\partial x_{i}}=-\frac{\partial J_{i^{\prime}, i}}{\partial x_{i}}+S_{i^{\prime}}, \\
J_{i^{\prime}, i}=-\rho D_{i^{\prime}, m} \frac{\partial m_{i^{\prime}}}{\partial x_{i}},
\end{gathered}
$$

Where $S_{i}, F_{i}$ and $S_{h}$ represent the source terms and $J_{i, i}$, the diffusion flux of species $i^{\prime}$. Flow may be considered as a turbulent flow because the wind induces it. For this reason, the model adopted assumes turbulent flow in the domain. The well-known $\mathrm{k}-\varepsilon$ model has been employed. Among all two-equation turbulence models, this one has been chosen due to its less computational effort. 


\subsubsection{Discrete phase model}

The dispersed phase consists of spherical water droplets of $\mathrm{D}_{\mathrm{p}}$ diameter dispersed in the continuous phase. The trajectory of a discrete phase particle (droplet) may be predicted by integrating the force balance on the particle, which is written in a Lagrangian reference frame. This force balance equates the particle inertia with the forces acting on the particle, and can be written as equation (6). The energy balance in the particle is considered in equation (8).

$$
\begin{aligned}
\frac{\mathrm{d} V_{p}}{\mathrm{~d} t}=\frac{18 \mu}{\rho_{p} D_{p}^{2}} \frac{C_{D} \operatorname{Re}}{24}\left(V-V_{p}\right)+g \frac{\left(\rho_{p}-\rho\right)}{\rho_{p}}+\frac{\rho}{\rho_{p}} V_{p} \frac{\partial V}{\partial r_{p}}, \\
\frac{\mathrm{d} r_{p}}{\mathrm{~d} t}=V_{p}, \\
m_{p} C_{p} \frac{\mathrm{d} T_{p}}{\mathrm{~d} t}=h A_{p}\left(T-T_{p}\right)+\frac{\mathrm{d} m_{p}}{\mathrm{~d} t} h_{f}, \\
\operatorname{Re}=\frac{\rho D_{p}\left|V_{p}-V\right|}{\mu}, \\
C_{D}=a_{1}+\frac{a_{2}}{\operatorname{Re}}+\frac{a_{3}}{\operatorname{Re}^{2}}, \\
F_{D}=\frac{18 \mu}{\rho_{p} D_{p}^{2}} \frac{C_{D} \operatorname{Re}}{24},
\end{aligned}
$$

Where coefficients $a_{1}, a_{2}$ and $a_{3}$ are constants used for smooth spherical particles over several ranges of Re given by Morsi and Alexander, 1972, $F_{D}\left(V-V_{p}\right)$ is the drag force per unit particle mass, $\mathrm{g} \cdot\left(\rho_{\mathrm{p}}-\rho\right) / \rho_{\mathrm{p}}$ is the gravity force per unit particle mass, $\left(\rho / \rho_{p}\right) V_{p}$ $\left(\partial V / \partial r_{p}\right)$ is the force caused by the pressure gradient in the fluid, and $\mathrm{dm} / \mathrm{dt}$, the evaporation rate on the particle.

\subsubsection{Coupling between discrete and continuous phase}

The process of coupling between the discrete and the continuous phase is solved by an iterative method. As the trajectory of a particle is computed, the algorithm keeps track of the heat, mass, and momentum gained or lost by the particle stream that follows that trajectory and these values can be incorporated in the subsequent continuous phase 
calculations. Thus, while the continuous phase always affects the discrete phase, the effect of the discrete phase trajectories on the continuum can be also incorporated. This two-way coupling is accomplished by alternately solving the discrete and continuous phase equations until the solutions in both phases have ceased to change. The source term in the continuity conservation equation (1) may be written as

$$
S_{i^{\prime}}=\frac{\Delta m_{p} \dot{m}_{p_{o}}}{m_{p_{o}} \mathrm{~d} \forall}
$$

Where $\Delta \mathrm{m}_{\mathrm{p}}$ is the particle mass change in each volume differential $\mathrm{d} \forall$ in a dt; $\dot{m}_{p_{o}}$, the initial mass flow rate of the injected particle tracked and $m_{p_{o}}$, the initial mass of the particle. This particle mass change in each $\mathrm{d} \forall$ may be expressed by

$$
\Delta m_{p}(\mathrm{~d} \forall)=m_{p}(t)-m_{p}(t-\mathrm{d} t)=N_{v} M_{v} A_{p} \mathrm{~d} t,
$$

Where $\mathrm{d} t=\mathrm{d} s /\left|V_{p}+V\right|$, and $\mathrm{ds}$ is the fraction of trajectory inside each volume differential $\mathrm{d} \forall$ considered; $\mathrm{M}_{\mathrm{v}}$ is the molecular weight of vapor, $\mathrm{A}_{\mathrm{p}}$ is the droplet area and $\mathrm{N}_{\mathrm{v}}$ is the molar flux of vapor:

$$
N_{v}=K_{c}\left(C_{v, s}-C_{v}\right)
$$

Where $C_{V, S}$ is the vapor concentration on the droplet surface and $C_{V}$, the vapor concentration in the bulk gas:

$$
C_{v, s}=\frac{p_{v s}\left(T_{p}\right)}{R\left(T_{p}\right)} \quad C_{v}=\frac{p x_{v}}{R T}
$$

With $\mathrm{x}_{\mathrm{v}}$ being the mass fraction of vapor. Mass transfer coefficient $\mathrm{K}_{\mathrm{c}}$ is obtained by a correlation of the Nusselt number given by Ranz and Marshall, 1952.

$$
K_{c}=\frac{\mathrm{Nu} D_{v, m}}{D_{p}}=\frac{\left(2+0,6 \cdot \mathrm{Re}^{1 / 2} \mathrm{~S}_{\mathrm{c}}^{1 / 3}\right) D_{v, m}}{D_{p}}
$$

Source terms of momentum equation (2) $F_{i}$ and energy equation (3) $S_{h}$, are given by the following expressions:

$$
F_{i}=\left(\frac{18 \mu}{\rho_{p} D_{p}^{2}} \frac{C_{D} \operatorname{Re}}{24}\left(V-V_{p}\right)+g \frac{\left(\rho_{p}-\rho\right)}{\rho_{p}}+\frac{\rho}{\rho_{p}} V_{p} \frac{\partial V}{\partial r_{p}}\right) \frac{\dot{m}_{p_{o}} \mathrm{~d} t}{\mathrm{~d} \forall}
$$




$$
S_{h}=\left[\frac{\bar{m}_{p}}{m_{p_{o}}} C_{p} \Delta T_{p}+\frac{\Delta m_{p}}{m_{p_{o}}}\left(-h_{f}+\int_{T_{r e f}}^{T_{p}} C_{p, i} \mathrm{~d} T\right)\right] \frac{\dot{m}_{p_{o}}}{\mathrm{~d} \forall},
$$

Where $\bar{m}_{p}$ is the average mass of the particle in control volume $\mathrm{d} \forall$ and $\Delta \mathrm{T}_{\mathrm{p}}$, the temperature change of the particle in control volume $\mathrm{d} \forall$. 


\section{$2.3 \quad$ Numerical model}

This system of equations has been numerically solved through a 3D model using the general-purpose code Fluent, based on a finite volume procedure (Fluent, 2003). The standard $k-\varepsilon$ turbulence model was used and the simple algorithm is utilized to solve the coupling between continuity and momentum equations through pressure. All calculations were performed using discretization providing second order accuracy. The convergence criterion in each case was $\left(\phi^{(i+1)}-\phi^{(i)}\right) / \phi^{(i)}<10^{-4}$, where $i$ denotes the iteration number and $\phi$ can stand for any of the dependent variables.

As stated above, numerical simulation was performed on a domain with a length of 3000 $\mathrm{m}$, a width of $1000 \mathrm{~m}$ and a height of $750 \mathrm{~m}$. The cooling tower was centred $500 \mathrm{~m}$ downwind of the entrance. The simulated hyperbolic cooling tower was modelled by using a hyperbolic profile with a rho parameter of 0.65 (necessary for defining the hyperbolic profile) and with its physical dimensions, i.e. a height of $124 \mathrm{~m}$, a base diameter of $114 \mathrm{~m}$ and an exit diameter of $54.8 \mathrm{~m}$.

In order to ensure the accuracy of numerical results, a grid dependence study was performed in the analysed domain. Domain's mesh is divided into two main zones: from the ground up to a height of $500 \mathrm{~m}$ tetrahedral cells are used, and above this zone hexahedral cells define a structured zone that completes the domain. Several meshes of different size were tested and the mesh of size 762969 cells was found to guarantee grid independent results (see Figure 2). Refining the mesh further did not produce any appreciable change in results. Complementary studies demonstrated that with a Reynolds number of $1.67 \cdot 10^{7}$ and domain ratio $\mathrm{L} / \mathrm{d}$ (where $\mathrm{L}$ is domain width and $\mathrm{D}$ the average diameter of the cooling tower) of 13.62 , symmetry boundary conditions for domain sides did not affect the results. A similar study was carried out in order to demonstrate that symmetry boundary condition for domain's top did not affect the results when it was located higher than 750 meters from the cooling tower exit surface. 


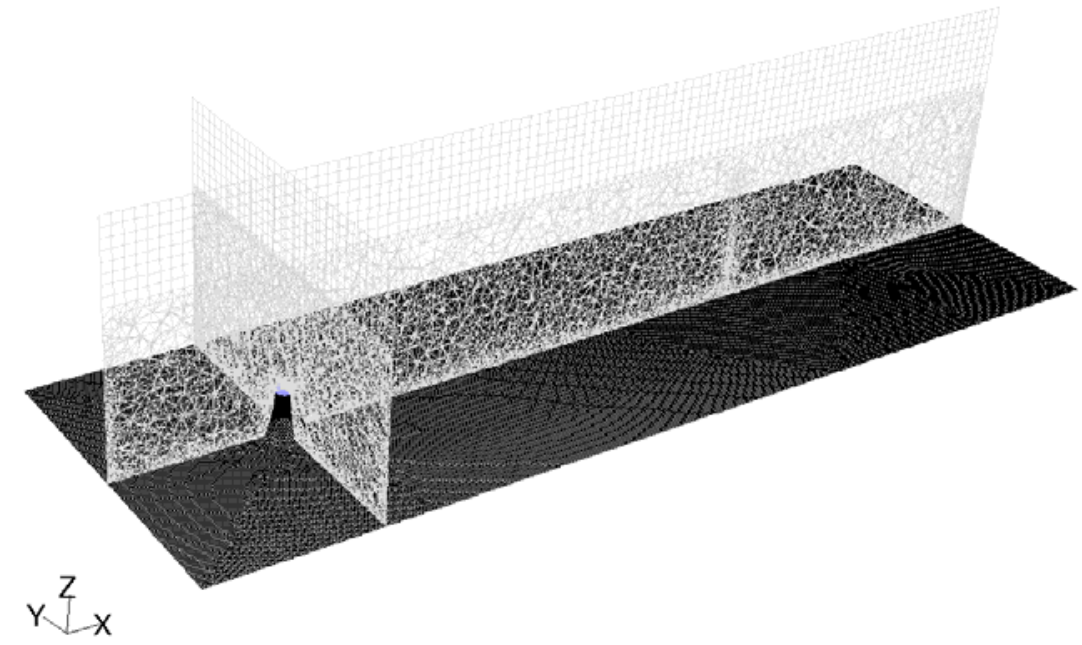

Figure 2: Mesh employed in the numerical simulation composed of tetrahedral and hexahedral cells.

The boundary conditions required for the present problem will now be described (see Figure 3). Wall boundary condition was selected for ground surface and for cooling tower surface. Non-slip conditions were imposed on the walls. Besides, the heat flux was zero and numerical option "trap" were set for accretion/deposition in walls. Symmetry boundary condition was selected for domain sides and top. The domain inlet conditions (wind velocity, temperature and absolute humidity) were set to as profiles. Pressure outlet boundary condition was selected for domain exit. Conditions at cooling tower exit (air velocity, temperature and absolute humidity) were set to constant values. Water mass flow was distributed uniformly on the surface. Droplet size distribution injection at cooling tower exit was defined as a Rosin-Rammler's equation with basing on the assumption that an exponential relationship exists between droplet diameter Dp, and mass fraction $M_{D_{p}}$ of droplets with diameter greater than $\mathrm{D}_{\mathrm{p}}$ :

$$
M_{D_{p}}=e^{-\left(\frac{D_{p}}{\bar{D}}\right)^{n}}
$$

where $\bar{D}$ is the average droplet diameter and $\mathrm{n}$ is a fit coefficient. Evaporating effects were considered and water liquid was the evaporating specie. Properties of moist air, such as moisture fraction, specific humidity, enthalpy, and others, were calculated through equations for psychrometric properties, derived from the fundamental equations for ideal gas mixtures. 


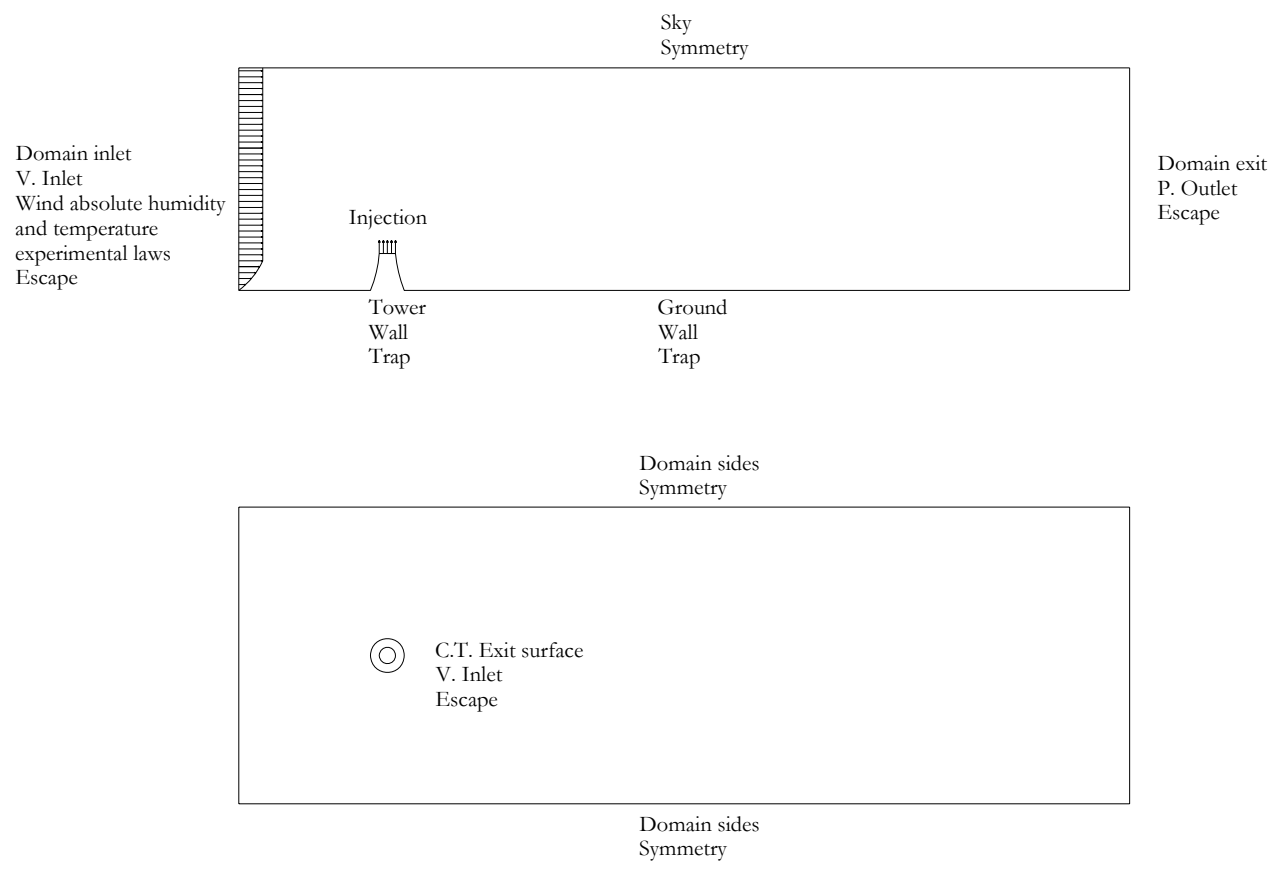

Figure 3: Summary of boundary conditions.

\section{Results and discussion}

\subsection{Validation of predicted results by experimental data}

Model validation was attempted by comparing the results from the numerical model with Chalk Point Dye Tracer Experiment data. This case was chosen for two reasons. On the one hand, this case was well documented and was easy to replicate (i.e. the source cooling tower was located in a flat unobstructed terrain, and plume rise, trajectory, wind, temperature and absolute humidity profiles were available), and on the other hand, a previous simulation developed by Meroney, 2006, had shown the CFD capacity to carry out this kind of studies. The model developed in this work considers droplet evaporation, a physical phenomenon which was not included in Meroney's model.

An environmental impact assessment study of the Chalk Point power plant was carried out on summer, 1977. Both, the Unit number 3 cooling tower and the stack effluent scrubber of the Chalk Point power plant produced salt water drift because of the brackish Patuxent River water used for the cooling tower and the stack particulate scrubbing agent. Drift 
measurements at Chalk Point used sodium as a tracer and consequently separation of cooling tower and stack drift was not possible. To provide a positive identification of the drift deposition from the individual sources, a water soluble fluorescent dye (Rhodamine W'T) was used as a tracer in the cooling tower circulating water. 30 gallons of $20 \%$ Rhodamine WT (fluorescent) dye were added to the cooling tower basin water, and no additional water was added to or drained from the basin during the experiment. The photolytically unstable dye required the experiment to be performed at night. The drift dye tracer experiment was conduced during a four-hour period on June the $16^{\text {th }}$ and $17^{\text {th }}$ of 1977. Drift deposition measurements were made placing the instruments at $5^{\circ}$ intervals on $35^{\circ}$ arcs at distances of $500 \mathrm{~m}$ and $1000 \mathrm{~m}$ of cooling tower number 3 exit surface (Figure 4).

Drift rates at the cooling tower exit were determined by using an instrument package suspended inside the tower in a plane approximately $13.6 \mathrm{~m}$ below its outlet section. The drift droplet size spectrum was measured using sensitive paper and a particle instrumentation by laser light scattering. The drift mass flux was measured with a heated glass bead isokinetic (HGBIK) technique. The updraft air velocity was measured using a Gill propeller type anemometer. Plant load remained constant during the experiment (on June the $16^{\text {th }}$ and $17^{\text {th }}$ of 1977). Source measurements reported a drift loss of $0.328 \mathrm{~kg} / \mathrm{s}$, which supposed a $0.002 \%$ of the water mass flow rate circulating through the Chalk Point cooling tower. Wind velocity, temperature and absolute humidity profiles were documented by JHU (1977). 


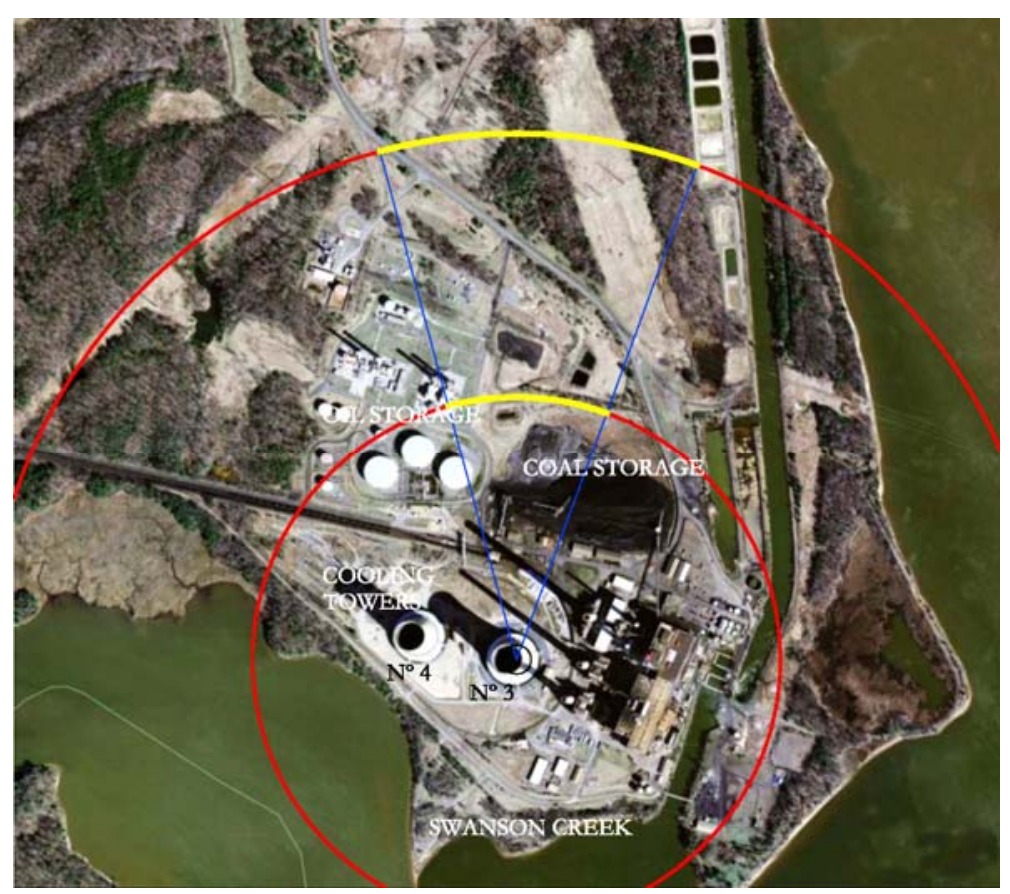

Figure 4: Sampling arrays at Chalk Point cooling tower number 3.

Regarding numerical model boundary conditions for the model validation, wind velocity was set, based on JHU data, to a power-law defined up to $100 \mathrm{~m}$ as

$v=0.3523 \cdot z^{0.6781}$

and with a constant velocity of $8 \mathrm{~m} / \mathrm{s}$ above $100 \mathrm{~m}$. Constant turbulence intensity of $10 \%$ and a length scale of $50 \mathrm{~m}$ were set at domain inlet. Temperature and absolute humidity were defined as the experimental profiles described in JHU report (1977). Conditions of air velocity, temperature and absolute humidity at the cooling tower exit were set to 4.5 $\mathrm{m} / \mathrm{s}, 315.3 \mathrm{~K}$ and $0.05552 \mathrm{~kg} / \mathrm{kg}$ constant values respectively. Constant turbulence intensity of $10 \%$ and length scales of $25 \mathrm{~m}$ were set. The exit water mass flow rate (distributed uniformly on the surface) was set to $0.328 \mathrm{~kg} / \mathrm{s}$ and the exit temperature was fixed to $315.3 \mathrm{~K}$. Droplet size distribution injection was defined as a Rosin-Rammler's equation with the following characteristic parameters: velocity $=4.5 \mathrm{~m} / \mathrm{s}$, (normal boundary); mean diameter $=9 \cdot 10^{-5} \mathrm{~m}$; shape factor $=0.65$ and " $\mathrm{n}$ " parameter $=80$.

In order to validate the numerical results, they were compared to Chalk Point experimental plume performance and drift deposition. Figure 5 shows temperature and mass fraction 
contours obtained with Fluent. The height of the centerline of the cooling tower plume was determined based on the height of the maximum in the water vapor (gaseous) profiles downwind of the cooling tower. These calculated points are included on Figure 6 as squares. The calculated points agree very well with the predictions of the Briggs plume rise formulae calculated by Hanna (1978) as well as with the magnitude of the visual observations for plume height recorded during the experiment.
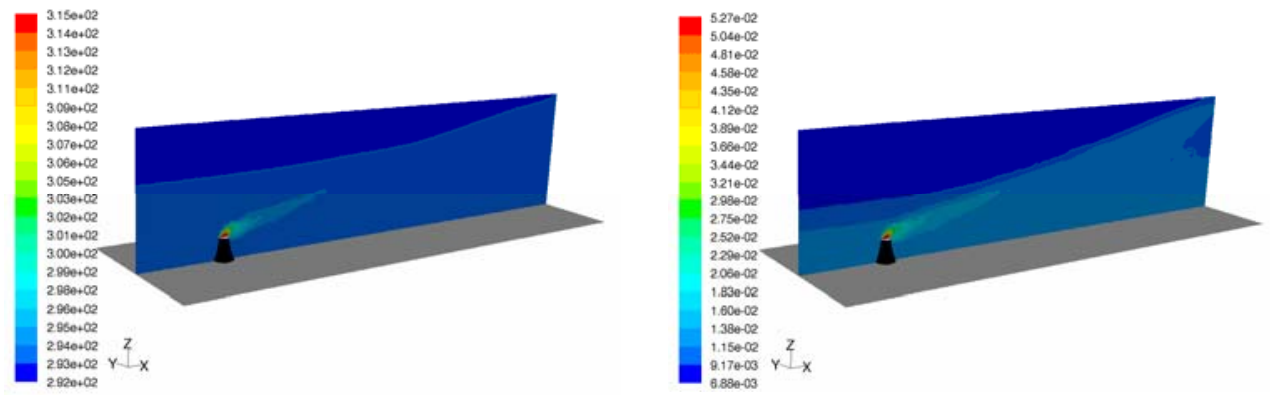

Figure 5: a) Temperature contours (K) and b) Mass fraction contours $(\mathrm{kg} / \mathrm{kg})$

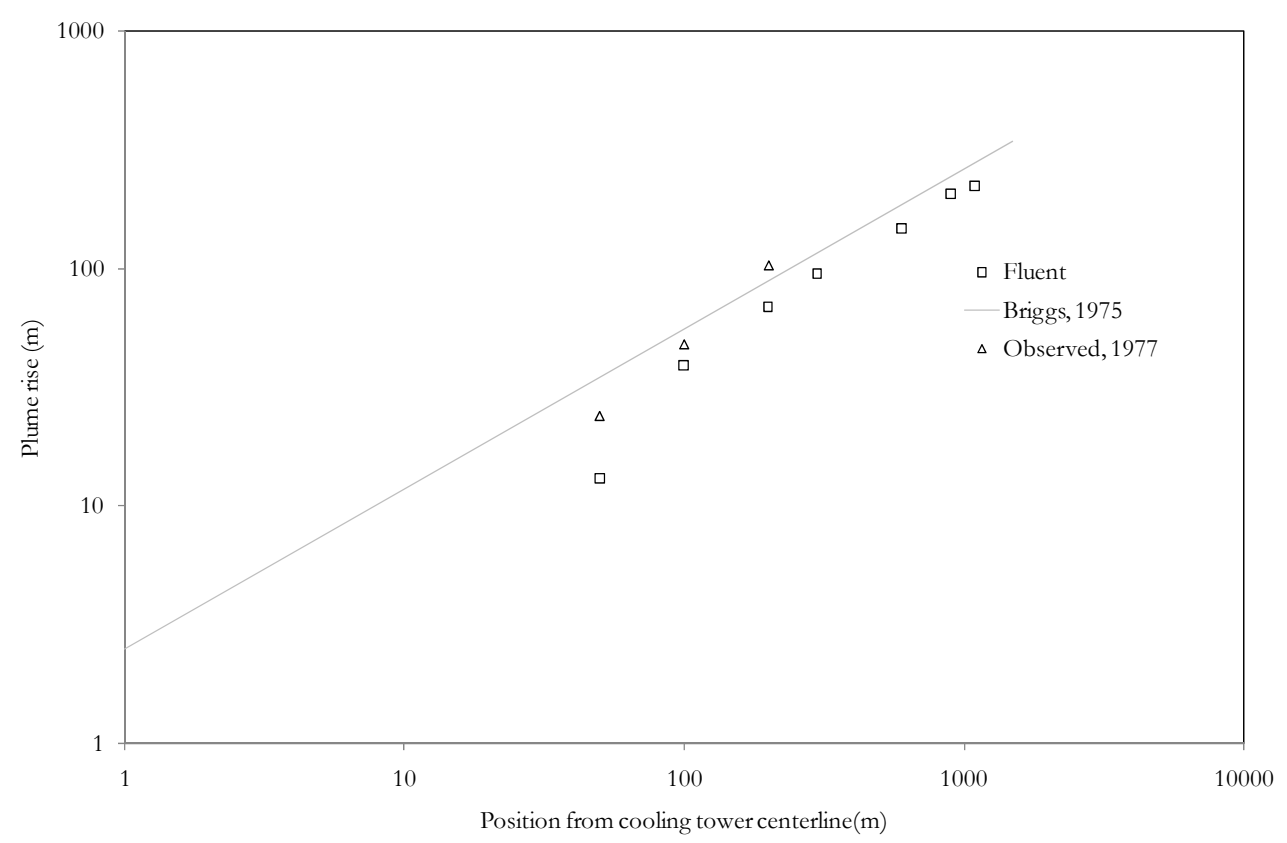

Figure 6: Predicted and observed cooling tower plume centerline trajectory during the Chalk Point Dye Tracer Experiment, June 16-17, 1977.

Regarding deposition, it was experimentally measured in Chalk Point in two different zones separated 500 and 1000 meters from cooling tower centreline respectively. Processing 
experimental data and considering a salt concentration of $0.014 \mathrm{gr} \mathrm{NaCl} / \mathrm{gr}_{2} \mathrm{O}$ water deposition values of $196.1 \cdot 10^{3}$ and $65.3 \cdot 10^{3} \mathrm{~kg} / \mathrm{km}^{2}$-mo resulted for the 500 and 1000 meters zones respectively. Figure 7 compares the numerical results obtained in this work with the previous numerical results from Meroney (2006) and with the experimental field results from Chalk Point. At the sight of this figure, it can be concluded that droplet evaporation was negligible during Chalk Point experiment because Meroney's results, which did not include this physical phenomenon, are quite similar to the numerical results obtained in this work. This result can be explained by the fact that field experiment was performed at night with a relative humidity of $93 \%$. Although previous reasoning was valid for the mentioned conditions, evaporation must be considered if the psychrometric ambient conditions are further enough from saturation line because it will play an important role on drift's evolution.

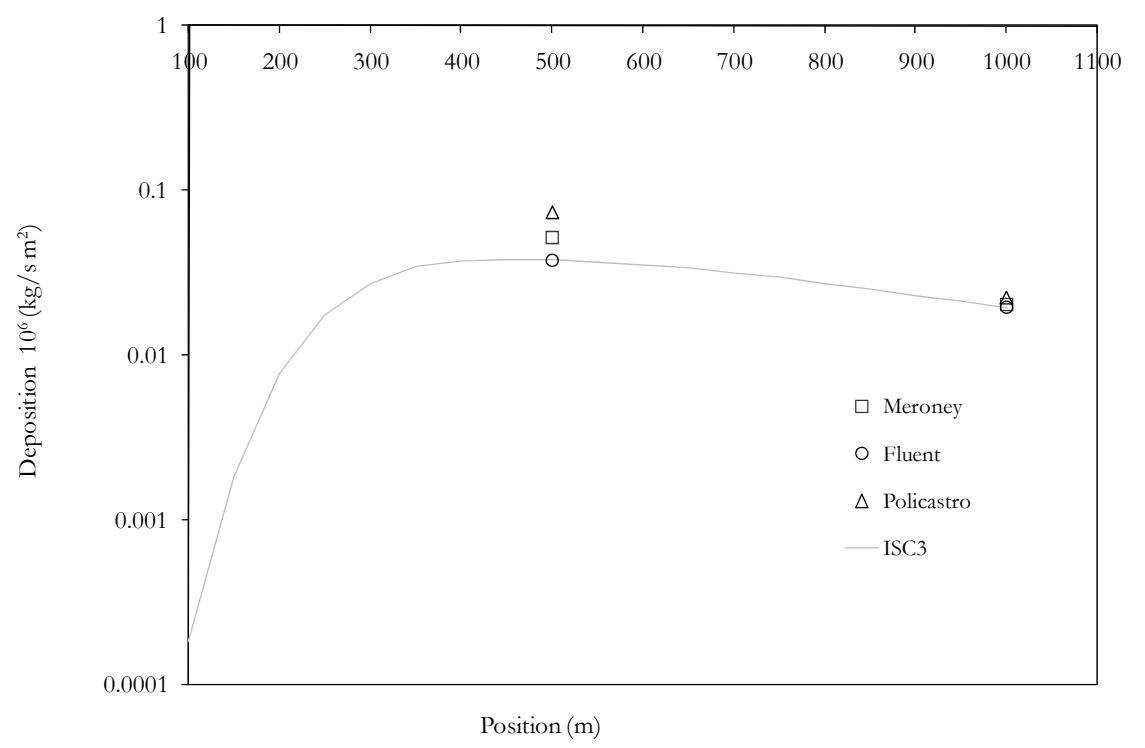

Figure 7: Comparison between CFD and Chalk Point experiment results. ACTUALIZAR 


\subsection{Numerical simulation of the influence of psychrometric ambient conditions on cooling tower drift deposition}

Once the numerical model was validated, the influence of psychrometric ambient conditions on cooling tower drift deposition was analyzed. Two independent psychrometric variables have been selected to describe ambient conditions: ambient dry bulb temperature and absolute humidity. Water droplet temperature at cooling tower exit was also included as a third variable. A Mediterranean-type climate corresponding to the south-east region of Spain ( $38^{\circ}$ latitude) was selected as reference. Interest in this region is justified because it has suffered several important outbreaks of Legionnaire's disease (Fernández et al., 2002 and Navarro et al., 2001). Average profiles for the days of summer, winter and spring were selected to be included in the numerical simulation considering meteorological data for the last twenty years. As it can be seen in Figure 8, Mediterraneantype climate is characterized by mild winters (temperature above $0^{\circ} \mathrm{C}$ ) and summers not too warm (temperature below $35^{\circ} \mathrm{C}$ ). For the absolute humidity, two levels were selected to describe a wet and a dry average days for every season as it is shown in Figure 9. The selected values for the water droplet temperature at the cooling tower exit were $305 \mathrm{~K}$ and $315.3 \mathrm{~K}$ for the low and the high level respectively. Everyone of the twelve cases evaluated is identified in Table 1.

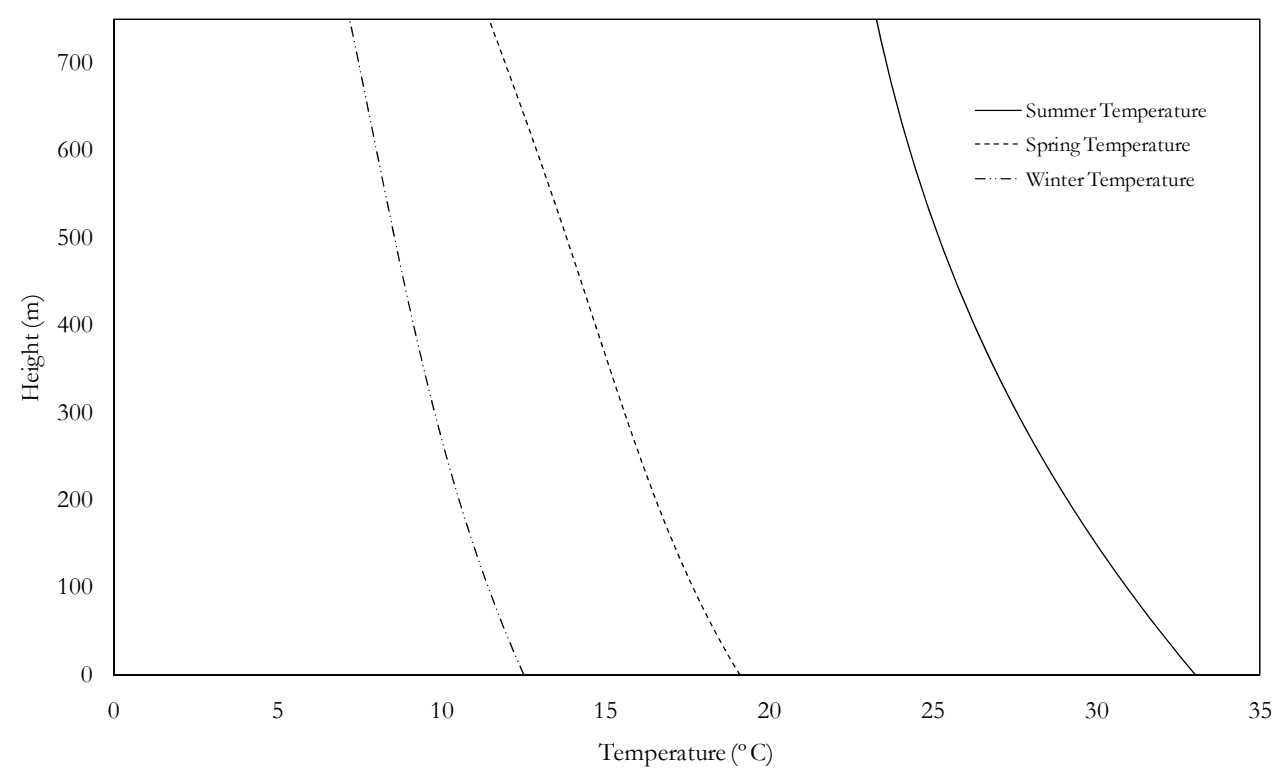

Figure 8: Ambient dry bulb temperature profiles 


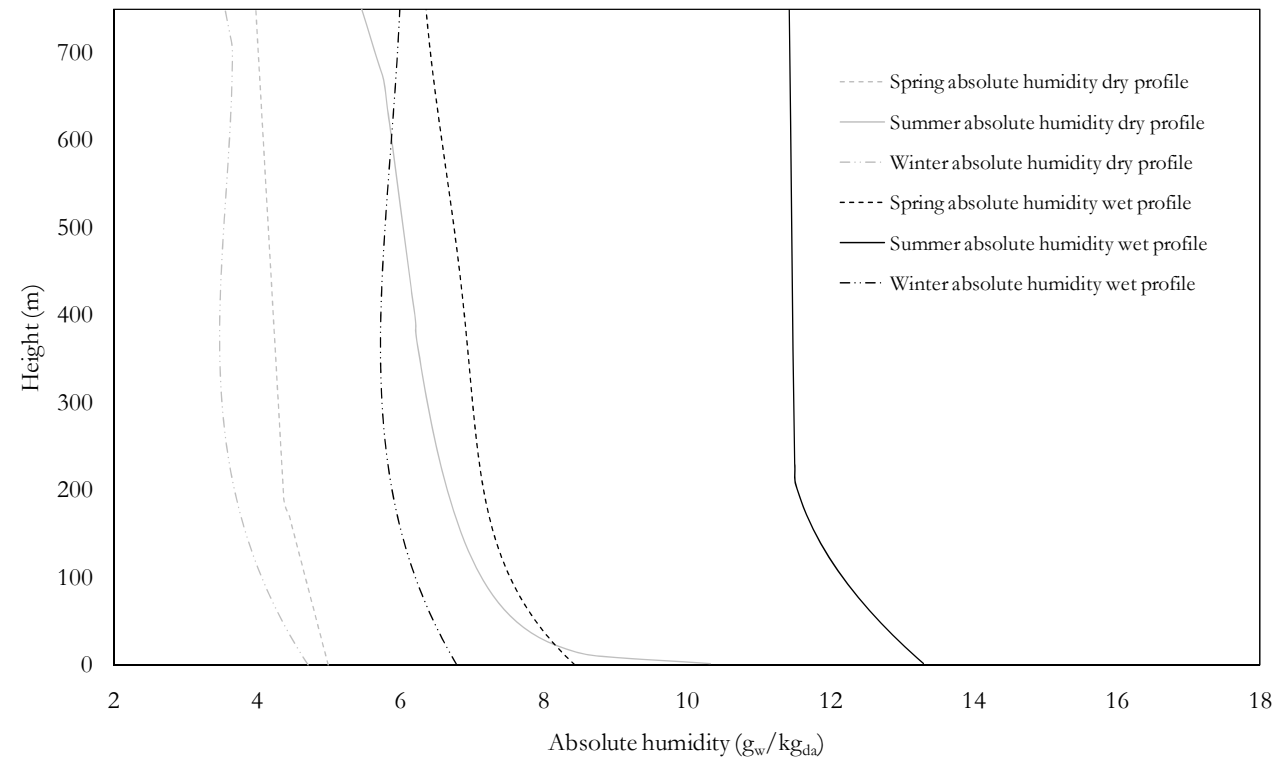

Figure 9: Absolute humidity profiles $\left(g_{\mathrm{w}} / \mathrm{kg}_{\mathrm{da}}\right.$ ) 


\begin{tabular}{|c|c|c|c|c|c|}
\hline Case & $\begin{array}{c}\text { Ambient temperature } \\
\text { level }\end{array}$ & $\begin{array}{c}\text { Ambient humidity } \\
\text { level }\end{array}$ & $\begin{array}{c}\text { Exit cooling tower water } \\
\text { temperature level }\end{array}$ & $\begin{array}{c}\text { Water deposition }(\mathrm{kg} / \mathrm{s}) \\
\cdot 10^{3}\end{array}$ & Affected distance (m) \\
\hline Case 1 & Winter & Dry & High & 328 & 1870 \\
\hline Case 2 & Winter & Wet & High & 498 & 2115 \\
\hline Case 3 & Spring & Dry & High & 256 & 1640 \\
\hline Case 4 & Spring & Wet & High & 430 & 1788 \\
\hline Case 5 & Summer & Dry & High & 129 & 1293 \\
\hline Case 6 & Summer & Wet & High & 210 & 1357 \\
\hline Case 7 & Winter & Dry & Low & 427 & 1796 \\
\hline Case 8 & Winter & Wet & Low & 752 & 2064 \\
\hline Case 9 & Spring & Dry & Low & 289 & 1519 \\
\hline Case 10 & Spring & Wet & Low & 479 & 1771 \\
\hline Case 11 & Summer & Dry & Low & 210 & 1250 \\
\hline Case 12 & Summer & Wet & Low & 407 & 1327 \\
\hline
\end{tabular}

Con formato

Table 1: Twelve cases included in the CFD study. 
Total water ground deposition values are shown in Table 1. These values were calculated as the integral of the deposition on the ground. Figure 10 shows the total water deposition on the ground per unit time and square meter along the x-coordinate for every 100 meters interval from null to 2100 meters, where the value 100 on the $x$-axis represents the first interval from the cooling tower perimeter.

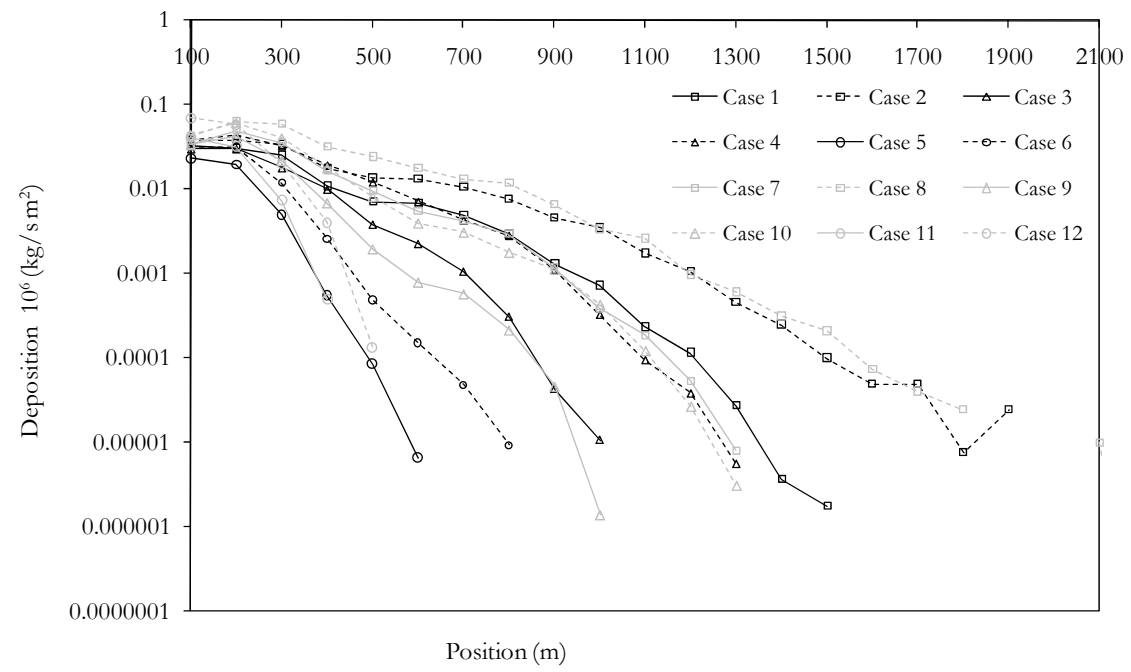

Figure 10: Predicted ground deposition results

"Affected distance" around the cooling tower is defined as the radius of the circle where $99 \%$ of the total water is deposed. These values are shown in Table 1 and denote the area affected by the cooling tower drift (Figure 11).

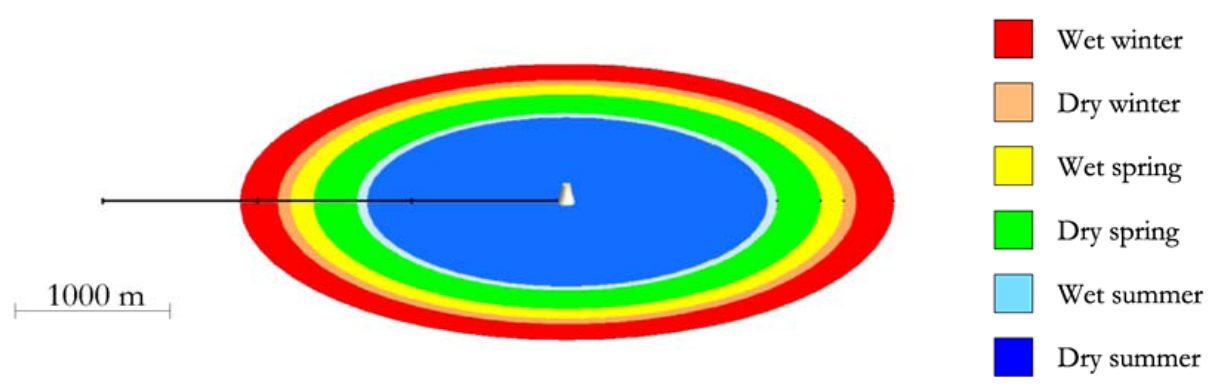

Figure 11: "Affected distance" in metres in cases from 1 to 6. 


\subsubsection{Influence of dry bulb ambient temperature}

Figure 12 shows how an increase in dry bulb temperature increases also droplet evaporation and therefore decreases ground deposition (keeping constant ambient absolute humidity and droplet temperature at the cooling tower exit). As the three cases have the same absolute humidity, wet bulb ambient temperature is higher in summer than in spring and in spring than in winter. So, as droplet water temperature stabilizes around wet bulb temperature, difference in vapour pressure between the water droplet surface and the ambient justifies the different levels of evaporation. Figure 13 shows how after the droplet leaves the cooling tower, its output temperature decreases to the ambient wet bulb temperature and after that it becomes stable around this value. This fact results in an integrated value of water mass deposed on the ground higher for winter cases than for summer cases. In the above mentioned conditions, the affected area becomes also larger as the ambient temperature decreases (see table 1).

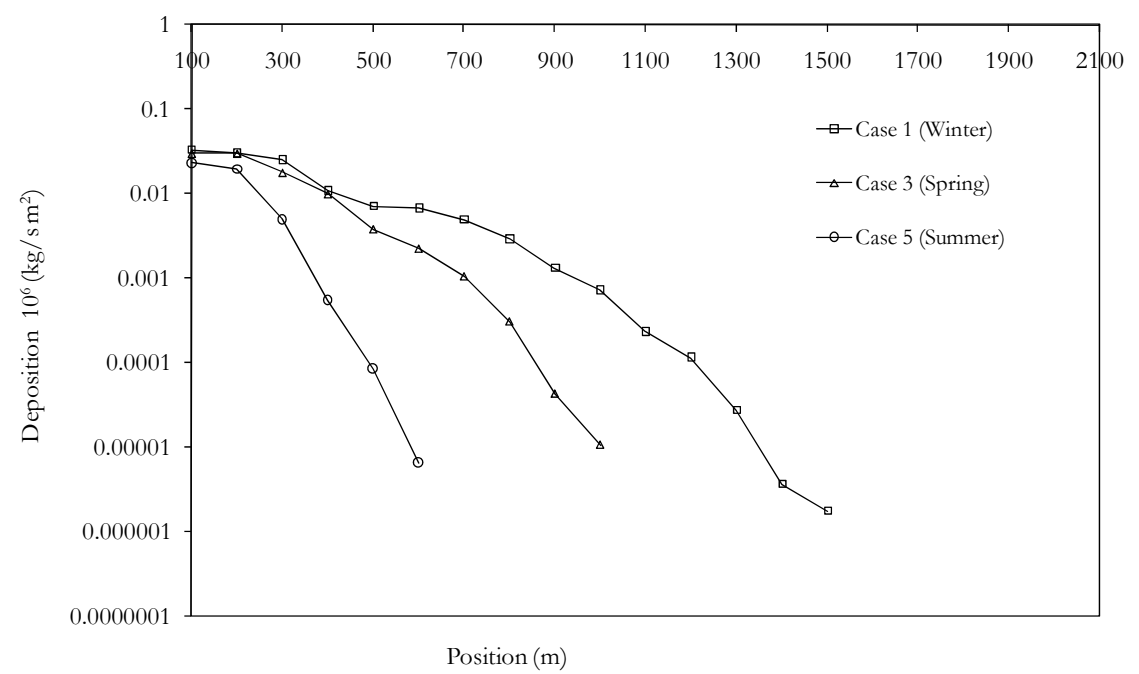

Figure 12: Influence of dry bulb ambient temperature on ground deposition (Dry, High $\mathrm{T}_{0}$ ). 


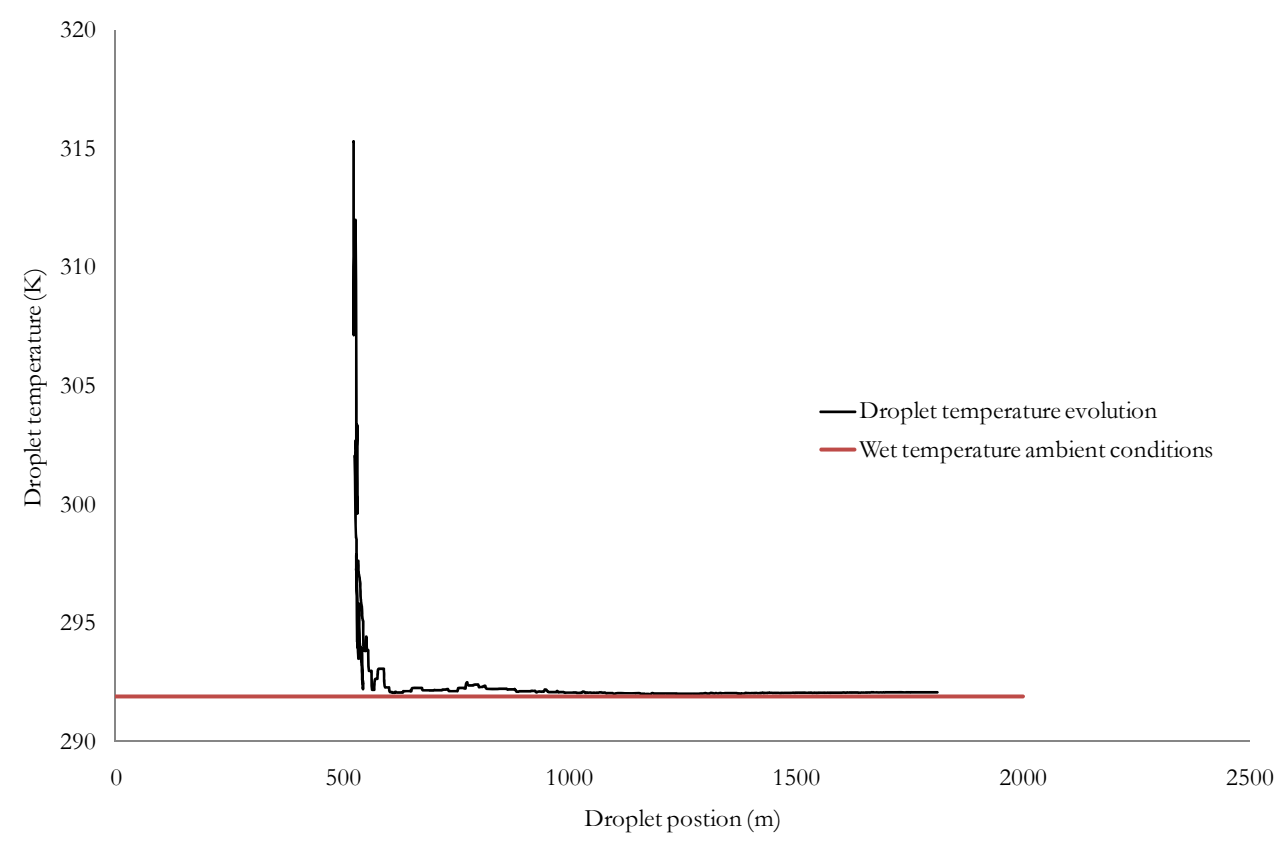

Figure 13: Predicted temperature evolution of a droplet (150 $\mu \mathrm{m}$ diameter).

\subsubsection{Influence of ambient absolute humidity $\left(\omega_{\infty}\right)$}

Figure 14 depicts the effect of ambient absolute humidity on ground deposition (keeping constant ambient temperature and output droplet temperature). As can be observed in Figure 14, evaporation is higher for dry cases and therefore mass deposed on the ground is lower than for wet cases. As it was justified in the preceding paragraph, the differences in vapour pressure between the water droplet surface and the ambient explain the different levels of evaporation. Consequently, the size of the zone affected by the cooling tower increases for wet cases and decreases for the dry ones (see Table 1). 


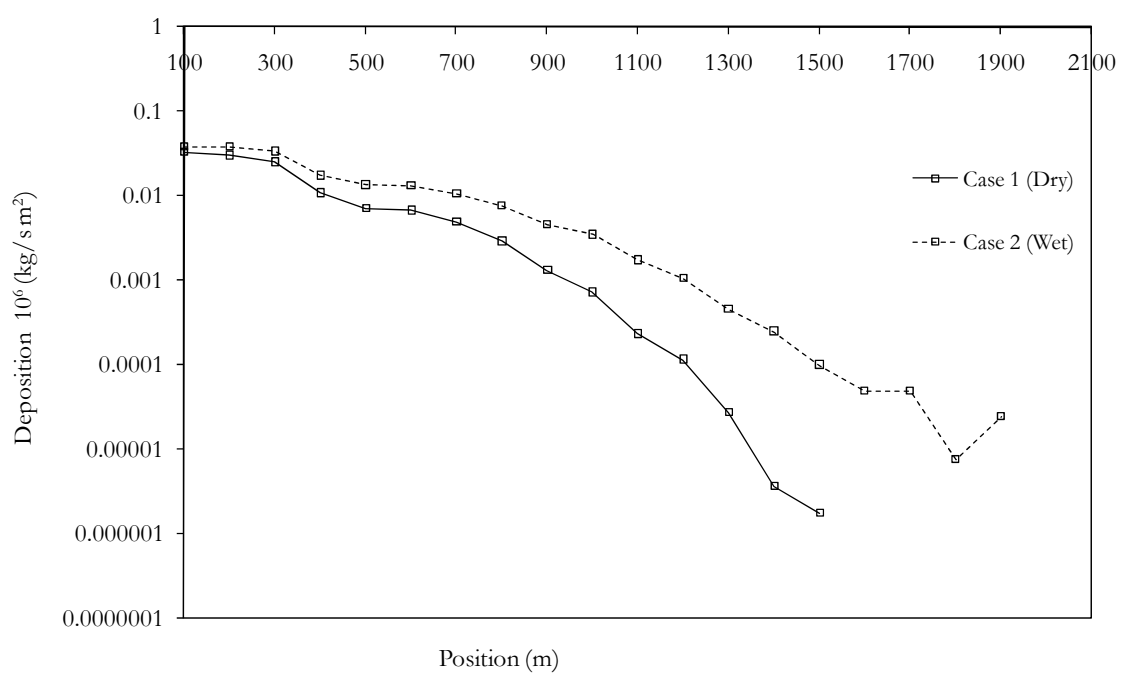

Figure 14: Influence of ambient absolute humidity on ground deposition (Winter, High $\mathrm{T}_{0}$ )

\subsubsection{Influence of output droplet temperature}

The effect of the droplet temperature at the cooling tower exit on ground deposition can be appreciated in Figure 15 where ambient dry bulb temperature and absolute humidity are kept constant. There is more evaporation in cases with a higher output droplet temperature because of the difference in vapour pressure between the droplet surface and the ambient. This fact occurs mainly during the evolution of the droplet temperature from the cooling tower exit temperature to the ambient wet bulb temperature. From this point evaporation becomes similar disregarding the droplets initial temperature as it also does the above mentioned difference in vapour pressure. According to this, the mass deposed on the ground results higher for lower output droplet temperatures.

Because of the higher evaporation, droplets with a higher temperature at the tower exit arrive at the wet bulb temperature with a smaller size. This fact justifies that, although deposition is lower, the radius of the zone affected by the cooling tower becomes greater as the smaller size of the water droplets makes them travel further (see Table 1). 


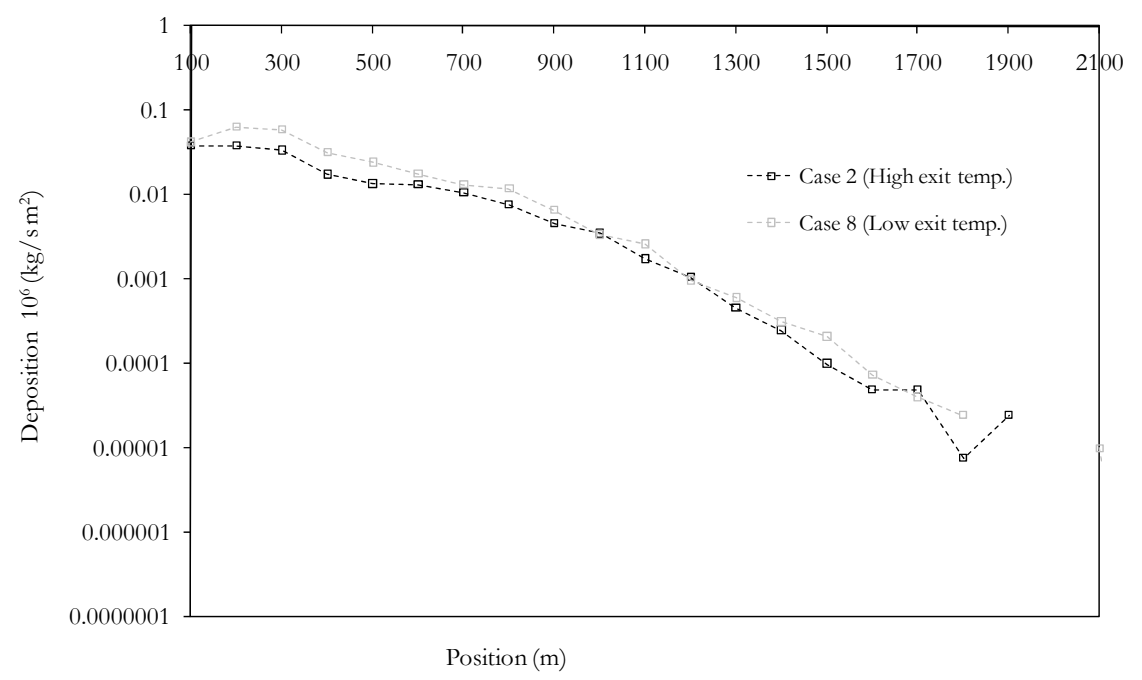

Figure 15: Influence of output droplet temperature on ground deposition (Winter, Wet) .

\subsubsection{Comparative effect of the influence of the studied variables on drift deposition}

Figure 16 shows the particle trajectories of four of the twelve cases analysed in this study. Wet winter with high output droplet temperature level has been selected as reference case (top left of Figure 16). Top right part of Figure 16 shows the particle trajectories for the wet summer high output droplet temperature level. It can be appreciate that the effect of the dry bulb temperature on the drift deposition is greater than the one corresponding to the absolute humidity (bottom left) or the one corresponding to the output droplet temperature (bottom right) for the range studied.

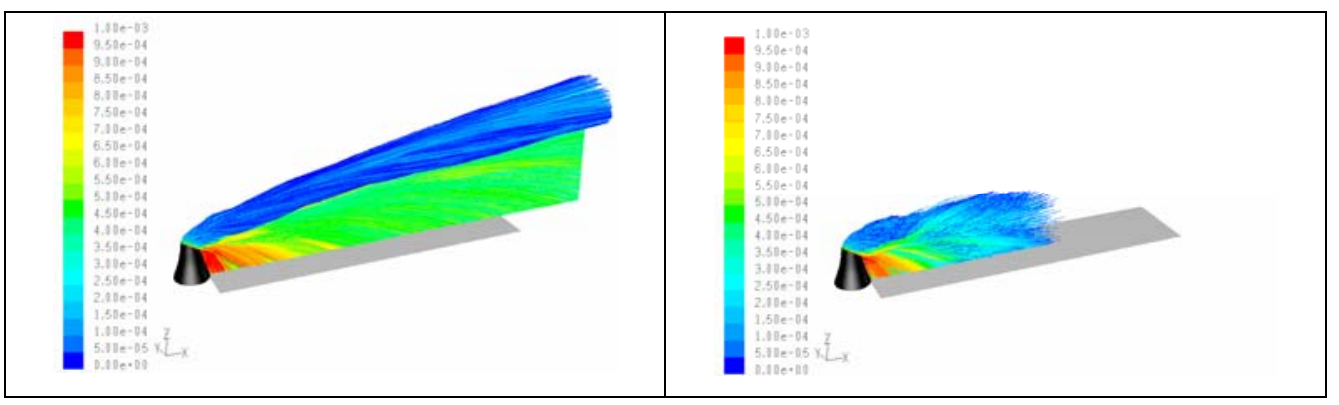




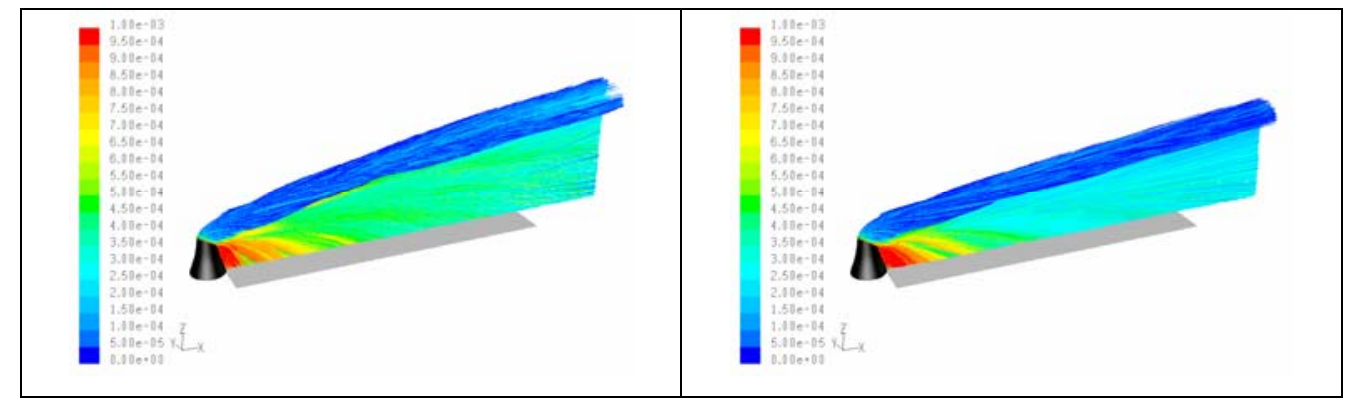

Figure 16. Images coloured by particle diameter (m) a) Top left: Wet winter high output droplet temperature level. b) Top right: Wet summer high output droplet temperature level. c) Bottom left: Dry winter high output droplet temperature level. d) Bottom right: Wet winter low output droplet temperature level. 


\section{Conclusions}

The objectives of this work were three-fold: the first one was to develop a computational fluid dynamics model to predict water droplet dispersion and surface drift deposition from cooling towers. The second one was to validate the model by using experimental data from literature. The third objective was to assess the influence of psychrometric ambient conditions (dry bulb temperature and absolute humidity) and water droplet exit temperature on drift deposition and on the size of the area affected by the cooling tower.

The mathematical model presented, consisting of two coupled sets of conservation equations for the continuous and discrete phases, was incorporated in the general purpose CFD code Fluent. Thus, a numerical finite-volume technique was used to simulate drift evaporation and deposition.

Experimental results from Policastro were employed to validate the numerical results in terms of plume performance and drift deposition. A good agreement was also obtained with the results provided by a previous numerical model developed by Meroney for the same experiment (Chalk Point Dye Tracer Experiment). Although Meroney's model did not take into account evaporation, the experiment was carried out in conditions of high relative humidity, which explains the lack of divergence between the results of both models.

Once it was validated, the model developed in this work showed the strong influence of ambient temperature on the cooling tower drift deposition and dispersion. With a higher ambient temperature, ground deposition was lower as it was also the zone affected by the cooling tower. The effect of the other two magnitudes included in the study (ambient absolute humidity and droplet output temperature) on the cooling tower drift deposition and dispersion was weaker than the one corresponding to the ambient temperature. A high level of ambient absolute humidity increased ground water deposition and also the radius of the drift dispersion area. Regarding the last variable, a high level of droplet output temperature decreased ground water deposition but increased the size of the zone affected by the cooling tower due to the fact that droplets with a higher temperature at the tower exit arrived at the wet bulb temperature with a smaller size, which made them travel further. 


\section{Acknowledgments}

The authors wish to acknowledge the collaboration of Dr. Robert Meroney (Wind Engineering and Fluids Laboratory, Civil Engineering Department, Colorado State University) who provided valuable information to this work. 


\section{References}

Lewis, B.G., 1974. On the question of airborne transmission of pathogenic organisms in cooling tower drift. Cooling Tower Institute. (Technical Paper- T-124A)

Pasquill, F., 1962. Section 6.2 Deposition of Airborne Materials, Atmospheric Diffusion: The Dispersion of Windborne Material from Industrial and Other Sources, D. Van Nostrand Company, Ltd., London, pp. 226-239.

Van der Hoven, I., 1968. Deposition of Particles and Gases, Meteorology and Atomic Energy 1968 (editor D. Slade), US. Atomic Energy Commission, pp. 202-207.

ASME, 1975. Mathematical Models for Drift Transport, Chapter 6, Cooling Tower Plume Modeling and Drift Measurement: A Review of the State of the Art, American Society of Mechanical Engineering, Three Park Avenue, New York, NY10016, pp. 64-76.

Pedersen, G.C., Lamkin, V.K. y Seich, M., 1987. An economical solution to cooling tower drift. Cooling Tower Institute. (Technical Paper- T-87-08).

Bentham R.H. and Broadbent C.R., 1993. A model autumn outbreaks of Legionnaries' disease associate with cooling towers, linked to system operation and size. Epidemiol Infect. 111 287-95.

Isozumi R., Ito Y., Ito I., Osawa M., Hirai T., Takakura S., Iinuma Y., Ichiyama S., Tateda K., Yamaguchi K. and Mishima M., 2005 An outbreak of Legionella pneumonia originating from a cooling tower. Scand J Infect Dis. 37(10) 709-11.

Wilmot, P., Pradhan, M., Hakendorf, P. y Bentham, R., (2000) Modelling cooling tower risk for legionnaries' disease using Bayesian networks and geographic information systems (GIS). 5th International Conference on Legionella Proceedings.

Brown C.M., Nuorti P.J., Breiman R.F., Hathcock A.L., Fields B.S., Lipman H.B., Llewellyn G.C., Hofmann J. and Cetron M., 1999. A community outbreak of Legionaries' 
disease linked to hospital cooling towers: an epidemiological method to calculate dose of exposure. International Journal of Epidemilogy 28 353-359.

US EPA, User's Guide for the Industrial Source Complex (ISC3) Dispersion Models: vol. II-Description of Model Algorithms, EPA-454/B-95-003b, 1995, pp. 1:5-1:30 and 1:351:46. (www.epa.gov/scram001/userg/regmod/isc3v2.pdf)

Policastro, A.J., Dunn, W.E., Gavin, P, Boughton, B., and Ziebarth, J., 1981. Studies on Mathematical Models for Characterizing Plume and drift Behavior from Cooling Towers, Volume 3: Mathematical Model for Single- Source(Single-Tower) Cooling Tower Drift Dispersion, CS-1683, Volume 3, Research Project 906-2, Argonne National Laboratory, prepared for Electric Power Research Institute, Palo Alto, CA.

Kennedy, J.F. and Fordyce, H., 1974. Plume recirculation and interference in mechanical draft cooling towers, Cooling Tower Environment-1974, Symposium at University of Maryland 4-6 March 1974, PPSP CPCTP-22, WRRC Special Report No. 9.

Jain, S.C. and Kennedy, J.F., 1978. Modeling Near-field Behavior of Mechanical Draft Cooling Tower Plumes, Environmental Effects of Cooling Tower Plumes, Symposium on, May 2-4, 1978, U. of Maryland, PPSP CPCTP-22, WRRC Special Report No. 9, pp. II-13 to II-30.

Petersen, R.L., 2004. ISC3 and PRIME Versus Wind Tunnel Observations for a Power Plant with Hyperbolic Cooling towers, 13th Conference on the Applications of Air Pollution Meteorology, Fifth Conference on Urban Environment, Vancouver, BC 23-26 August 2004.

Bahmann, W. and Schmonsees, N. Consideration of wind tunnel studies in dispersion calculations with the new model Austal2000-Case study: Discharge of flue gas vis cooling towers. Proceedings of $9^{\text {th }}$ Int. Conf. On Harmonisation with atmospheric dispersion 
modelling for regulatory purposes. Gasmisch-Partenkirchen, Germany, 1-4 June 2004, pp 188-191.

Bender, D.J., Kerksen, D., and Rezkallah, K.S. (1993), Numerical study of wind flow over a cooling tower, Journal of Wind Engineering and Industrial Aerodynamics, Vol. 46 \& 47, pp. 657-664.

Takata, K., Nasu, K., and Yoshikawa, H. (1996), Prediction of the Plume from a Cooling Tower, 1996 Cooling Tower Institute Annual Conference, Houston, TX - February 1996, 27 pp.

Bornoff, R.B. and Mokhtarzadeh-Dehghan M.R.. A numerical study of interacting buoyant cooling-tower plumes. Atmospheric Environment 35 (2001) pp. 589-598

Riddle, A. Carruthers, D. Sharpe, A. McHugh, C. and Stocker, J. Comparisons between FLUENT and ADMS for atmospheric dispersion modelling. Atmospheric environment 38, 2004, pp 1029-1038.

Meroney, R. N. 2006. CFD Prediction of Cooling Tower Drift. Journal of Wind Engineering and Industrial Aerodynamics 94 (2006) 463-490.

Hanna, S.R. (1974), Fog and Drift Deposition from Evaporative Cooling Towers, Nuclear Safety, Vol. 15, No. 2, March-April 1974 (also ATDL Contribution File No. 94)., pp. 190196.

Policastro, A.J., Dunn, W.E., Breig, M. and Ziebarth, J., 1978. Comparison of Ten Drift Deposition Models to Field Data Acquired in the Chalk Point Dry Tracer Experiment, 
Environmental Effects of Cooling Tower Plumes, Symposium on (Supplement), May 2-4, 1978, U. of Maryland, pp. 76-84.

A.J. Policastro, W.E. Dunn, M.L. Berg, J.P. Ziebarth, The chalk point dye tracer study: validation of models and analysis of .eld data, in: S.S. Lee, S. Sengupta (Eds.), Proceedings of second Conference on Waste Heat Management and Utilization, Miami Beach, Florida, December 4-6, 1978, pp. 686-719.

S.A. Morsi, A.J. Alexander, An investigation of particle trajectories in two-phase flow systems, J. Fluid Mech. 55 (2) (1972) 193-208.

W.E. Ranz, W.R. Marshall, Evaporation from drops, Part I, Chem. Eng. Prog. 48 (3) (1952) $141-146$.

Fluent 6.1 User's Guide (2003), Available on web by permission from Fluent at: http://www..uentusers.com/fuent61/doc/doc_f.htm

Johns Hopkins Univ., Laurel, Md. Applied Physics Lab. Chalk Point Cooling Tower Project. Volume 3. Cooling Tower Drift Dye Tracer Experiment Surface Weather and Ambient Atmospheric Profile Data, June 16 and 17, 1977. - Final rept. 1 Jul 76-30 Jun 77.

Fernández, J. A. López, P. Orozco, D. and Merino, J., 2002. Clinical Study of an Outbreak of Legionnaire's Disease in Alcoy, Southeastern Spain. Eur J Clin Microbiol Infect Dis. 21:729-735.

Navarro, C. et al. (2001). Update of the outbreak of legionaries' disseases in Murcia Spain. Eurosurvillance Weekly. 5(21). 